\title{
Deceptive Communication in Group Contexts
}

Jeremy R. Winget \& R. Scott Tindale

Loyola University Chicago

This paper has been accepted for publication and may be cited as:

Winget, J. R., \& Tindale, R. S. (2019). Deceptive communication in group contexts. In DocanMorgan, T. (Ed.), The Palgrave Handbook of Deceptive Communication (p. 605-624). Cham: Palgrave Macmillan. doi:10.1007/978-3-319-96334-1_32

Corresponding author: Jeremy R. Winget, jwinget@luc.edu 


\begin{abstract}
Unethical behavior is often viewed as an individual-level phenomenon. However, group membership can influence individuals' choices to behave ethically or not (Messick, 2006). This chapter discusses whether and when groups will be more likely than individuals to use deception. We focus on three areas of research. The first involves comparing individuals and groups in mixed-motive situations, and the discontinuity between individual and group responses to economic games: individuals tend to cooperate while groups tend to compete (Wildschut, Pinter, Veva, Insko, \& Schopler, 2003). In terms of deception, this is interesting as both individuals and groups initially cooperate. We discuss explanations for groups' unethical tendencies and their relation to why groups use deception. Second, we focus on general differences between individual and group deception. Deception can be beneficial when negotiating, and groups tend to use deception to their benefit (Cohen, Gunia, Kim-Jun, \& Murnighan, 2009; Sutter, 2009). Finally, we discuss explanations for these effects and provide a framework for understanding when and why groups use deception.
\end{abstract}

Key Words: Group Decision Making, Group Deception, Mixed-Motive Situations, Individual and Group Differences, Interindividual-Intergroup Discontinuity 
Prior to the 1960s, American manufactures dominated the automotive market. However, by the end of the decade, American automotive manufacturers' concerns began to rise with the increase of imported cars. Denying defeat, Ford Motor Company tried to remain competitive by producing the Pinto. Eager to have their subcompact ready, Ford condensed their typical drafting timeline, which meant that any design changes that were typically made before production would instead be made during it (Shaw \& Barry, 2001).

Before production Ford crash-tested various prototypes, partially to learn whether they met a safety standard proposed by the National Highway Traffic Safety Administration (NHTSA) that aimed to reduce fires in traffic collisions. The standard required that all new automobiles be able to withstand a rear-end impact of 20 miles per hour (mph) without fuel loss by 1972 (Shaw \& Barry, 2001). When Ford crash-tested their Pinto prototypes, all failed the 20 mph test. Later, Ford crash-tested the final version of the Pinto and found the same result: ruptured gas tanks and dangerous leaks.

Ford knew that the Pinto represented a serious fire hazard when struck from the rear and faced a decision: (1) keep the existing design, thereby meeting the production timetable but jeopardizing consumer safety; or (2) delay production of the Pinto by redesigning the gas tank to make it safer and concede another year of subcompact dominance to foreign manufacturers. Ford ultimately pushed ahead with the original design and continued to use it for the next six years (Shaw \& Barry, 2001). Ford has always denied that the Pinto is unsafe compared to other cars of its type and era. The company also argues the Pinto met or surpassed the government's own standards in every model year. However, they neglect to mention that successful lobbying by them and industry associates was responsible for delaying the adoption of any NHTSA crash standard for seven years (Shaw \& Barry, 2001). 
There are many instances in which groups and organizations have made choices that, from an outside observer's perspective, were easily seen as unethical. Companies such as Enron, British Petroleum, Volkswagen, and a number of major banks and political groups have made decisions that were in their short-term interests while knowing their behavior was either misleading or, in some cases, obviously harmful to at least some of their constituents. Often, the leaders of such organizations are seen as the culprits and are blamed, sued, and sometimes indicted and convicted. However, the major decisions made by companies are rarely attributable to a sole individual. It is often the cooperation of corporate boards and management teams that make most of the decisions for an organization. Therefore, it is quite likely unethical behavior and deception by organizations is at least partially a function of unethical decisions and deception made by groups within the organization.

There is now a fair amount of research on unethical behavior (e.g., deception) in and by groups (for a review, see Messick, 2006). Even in situations where individuals behave cooperatively and abide by prior agreements, groups often defect (i.e., choose a noncooperative response/break agreement to cooperate) from such agreements in order to protect or enhance the group (Wildschut, Pinter, Vevea, Insko, \& Schopler, 2003; Morgan \& Tindale, 2002). Thus, groups are likely to use the group's welfare to guide their "moral compass" and behave in ways consistent with their self-interest even when it violates typical norms of ethics (Cohen, Gunia, Kim-Jun, \& Murnighan, 2009). This "group morality" (Wildschut \& Insko, 2006) or group enhancement/protection norm (Tindale, 2008), at times, seems to guide group behavior in directions opposite those typically found for individuals. Groups often exacerbate tendencies found for individuals (i.e., group polarization, Stasser, Kerr, \& Davis, 1989; Kameda, Tindale, \& 
Davis, 2003), so this discontinuity (Wildschut et al., 2003) is somewhat unique in research on groups and has proved very difficult to change (though see Pinter et al., 2007).

Moreover, there are general differences between individuals and groups in deception use. Research shows deception can be beneficial when negotiating, and groups tend to use deception to their benefit more than individuals (Cohen et al., 2009; Sutter, 2009). Furthermore, under certain circumstances, groups strategically use honesty to maximize their outcomes. However, other research shows lying is more pronounced under team incentives than individual piece-rates (Conrads, Irlenbusch, Rilke, \& Walkowitz, 2013). We discuss explanations for these effects and situations where groups would be more versus less likely to use deception. Finally, based on concepts of social identity theory and ingroup bias (Hogg \& Abrams, 1988) and work on group decision making (De Dreu, Nijstad, \& Van Knippenberg, 2008), we provide a framework for understanding when and why groups use deception.

The ideas underlying the current chapter are drawn from a number of theoretical perspectives and empirical findings. Much of the literature reviewed in this chapter is based on laboratory-based experiments and research involving economic games. Although such research can, at times, be criticized as being artificial, these studies provide compelling empirical evidence for several reasons. First, these experiments help to eliminate individual differences by randomly assigning participants to conditions. Second, using a true experiment helps to eliminate other kinds of confounds as well. Third, these studies capitalize on situational control afforded by the laboratory, which can reduce noise in the outcome measures. Fourth, laboratory studies allow researchers to systematically blend multiple independent variables in order to see how they work together (i.e., statistical interactions) to determine behavior. A final strength of laboratorybased studies is that they provide a unique ability to minimize noise in measurement. Despite 
these many benefits, there are nevertheless some drawbacks in the use of the experimental design. As mentioned, the biggest issue relates to artificiality. To counter this limitation, researchers often try to increase the experimental realism (i.e., the desired psychological state) of the study.

Therefore, the current chapter organizes the group deception literature by first comparing individuals and groups in mixed-motive situations. There is a discontinuity between individual and group responses to games (e.g., prisoner's dilemma): individuals tend to cooperate while groups tend to compete (Wildschut et al., 2003). In terms of deception, this is interesting as both individuals and groups initially agree to cooperate. We discuss explanations for the effect and their relation to why groups deceive. We then discuss the general differences between individuals and groups in deception use and conclude with a framework for understanding when and why groups use deception.

\section{Mixed-Motive Situations}

Groups, by their very nature, have a normative tendency to behave in ways that benefit the group. This has been referred to as the group enhancement/protection norm (Tindale, 2008), in that groups act to both enhance their well-being (e.g., status, wealth) and protect themselves from threats outside the group (often from other groups). This norm is likely a function of evolutionary adaptive pressures associated with the fact that humans live within group contexts (Brewer \& Caporael, 2006; Kameda \& Tindale, 2006). Because human survival depended on groups remaining together to hunt and fend off predators, groups that could induce members to work toward enhancing and protecting the group were more likely to survive, as were their members. These tendencies are still present in groups today and can be beneficial in many contexts (e.g., communities pulling together to share resources after a disaster). However, there 
are situations where the good of the group is not good for non-members or for society at large. For example, company executives may see lying to shareholders so they do not remove their investments from a company as necessary for the company's survival, but it is neither good for the shareholders or for other non-company agents (e.g., clients). In a general sense, deception such as this would be seen as unethical. However, from the perspective of the company executives, the behavior may be seen as necessary for survival and thus acceptable. Below, we discuss research and theoretical reasons for why groups would be more likely to behave unethically in these types of situations than would single individuals.

Perhaps the most well-known demonstration of groups being more likely to engage in self-protection compared to individuals concerns the interindividual-intergroup discontinuity effect (Schopler \& Insko, 1992; Wildschut et al., 2003), a well-replicated finding in the small group literature. The basic finding shows a discontinuity between interindividual and intergroup exchanges in mixed-motive situations (i.e., a situation in which an individual or group is tempted to either cooperate or compete). That is, when two individuals communicate while making choices in a prisoner's dilemma game (i.e., a situation in which two people each have two options whose outcome depends on the simultaneous choice made by the other person), they typically agree to cooperate and then subsequently do so when making their individual choices. However, when two small groups play the same game, they agree to cooperate during communication but then typically defect when making their choices. Thus, the discontinuity arises from the finding that rather than exacerbate the dominant individual tendency toward cooperation, groups move in a direction opposite of the individual tendency. This finding conflicts with two well substantiated and related group phenomena: majority factions tend to win and groups tend to polarize. 
A number of different explanations for this phenomenon have been proposed (for a review, see Wildschut \& Insko, 2007), but research suggests that there are both group-level and intergroup-level aspects to the basic effect. Morgan and Tindale (2002) did focused analysis of the group processes involved in the discontinuity effect. Using a mixed-motive game, they had groups play against other groups or had groups play against individuals. They found the discontinuity effect was stronger when a group was playing against another group (see also Wildschut, Insko, \& Pinter, 2007) but was still present when groups played against individuals. When playing against another group, groups often fear being taken advantage of so they defect (i.e., compete) to protect the group. However, when they play against individuals, they no longer fear being taken advantage of, but more often use greed as their justification for defection. Morgan and Tindale's (2002) second major finding was that simply being in a group tended to lead to greater individual preferences among the group members for defection. However, the change was rather small and the majority faction within most groups still typically favored cooperation. Thus, a standard majority wins model would predict groups to be generally cooperative. In contrast, they found that factions favoring defection were more influential than factions favoring cooperation regardless of faction size. In groups where one member preferred defection and two members preferred cooperation prior to group discussion (i.e., the majority faction preferred cooperation), the majority faction only won $33 \%$ of the time. Majority factions preferring defection won $88 \%$ of the time. Thus, factions that preferred defection were far more influential than factions that preferred cooperation.

Further evidence for the enhancement/protection norm is supported by group reactions to dishonesty. In two experiments, Keck (2014) showed dishonesty was punished more often by groups than by individuals, that groups' higher willingness to punish dishonesty was mediated by 
stronger negative affect, and that increased negative affect in groups is driven by exposure to other group members' negative feelings and opinions during group discussions. Keck (2014) randomly assigned participants to make a decision as a three-person group or an individual using a modified version of the deception game (Gneezy, 2005). The deception game is an decisionmaking task that requires one party (i.e., the sender) to send a truthful or deceptive message to another party (i.e., the receiver). Specifically, the sender learns of two payment options and is asked to send either a truthful or a deceptive message about the options to the receiver. Sending the truthful message potentially harms the sender's financial outcomes, whereas sending the deceptive message makes it likely the sender will benefit financially (e.g., earn $\$ 6$ instead of $\$ 5$ ). After receiving one of the messages, the receiver ostensibly chooses one of the two payment options based on the sender's message. Thus, the only information the receiver receives about the payoffs is the information included in the sender's message.

Since prior work demonstrated groups are more likely to send deceptive messages than individuals in the deception game (Cohen et al., 2009; Sutter, 2009), Keck (2014) focused on reactions to deceptive messages. Thus, all participants were assigned to the role of receiver and all senders were actually computers. In the game, receivers tried to guess a random number between 0 and 1000. Those who answered correctly earned $€ 7.50$ and all others received $€ 3.50$. Participants were told they were paired with another player (i.e., the sender) who knew the correct value of the number and would send them a message before they made their guess. Half of the participants were told the sender was another individual while the other half were told the sender was a group of three individuals. Senders were described as having an incentive to lie because a wrong guess by the receiver would result in a higher payoff for the sender (€7.50 versus $€ 3.50$ ). However, the sender's message was the only information the receivers were given 
to make their decision. In actuality, all participants were sent a deceptive message containing the same wrong number. After making their decision, participants were informed of the correct number.

Afterwards, participants were told the game would continue with a second stage. Participants were told at the beginning of the game would progress to the second stage or end after the first stage based on random assignment from a computer. In actuality, all participants progressed to the second stage. During the second stage, participants were given the option of spending some of their payoffs on punishing senders for sending them an incorrect number. Participants could spend between $€ 0.10$ and $€ 1.00$ (in 10-cent intervals) to lower senders' payoffs by four times the amount spent. Keck (2014) showed there were higher levels of mutually harmful spending on punishment when groups made punishment decisions. The effect was mediated by the stronger degree of negative affect that group members, relative to individuals, felt when interacting with a dishonest party. Results also showed that diffusion of responsibility did not function as an alternative mediator. There was no evidence that groups focused more than individuals on maximizing their financial self-interest when deciding whether to punish dishonest behavior. Also, willingness to punish dishonesty did not depend on the target of the punishment. Groups were punished just as much as individuals. This suggests group members' greater desire to punish dishonesty could be attributed to factors specific to group decision making rather than factors related to the source of the dishonest behavior.

Keck (2014) used the same procedure in a second study, but in order to focus on the factors that were driving the negative affect and punishment in groups, Keck measured negative affect twice in the group decision conditions: before (Time 1) and after (Time 2) the group discussion took place. The results again showed groups were more willing than individuals to 
punish dishonest behavior even if punishment was financially costly. As in Study 1, the effect was mediated by greater negative affect in groups compared to individuals. The results also showed that although there was no difference in negative affect between individuals and groups before the group discussion, group members reported significantly more negative affect than individuals after talking to each other. Thus, these results provide evidence that the heightened negative affect in groups was caused by the interaction among group members. Taken together, Keck's (2014) results suggest that being part of a group increases negative emotions toward dishonest others and leads to a greater willingness to utilize costly punishment in order to protect the ingroup.

Although there is evidence that groups will behave uncooperatively for strategic reasons (see Bornstein \& Yaniv, 1998), recent research has found that groups still choose defection in economic games where it is not the dominant response. Tindale and colleagues (2006) found similar asymmetries in social influence patterns (i.e., minority factions within a group favoring defection winning out over majority factions favoring cooperation) for groups playing games in which the mutual defection response was the worst option possible and the difference in payoff for cooperate/cooperate or cooperate/defect response combinations was very slight. The study involved multiple plays of the game and a single defection by either team at any point during the experiment tended to lead to mutual defection for all subsequent plays. Thus, groups tended to defect even when it was not economically rational to do so.

Additional research has also shown that group behavior in these settings is generally driven by concerns for the welfare of the ingroup rather than attempts to disadvantage the outgroup (Halvey, Bornstein, \& Sagiv, 2008). Halvey and colleagues (2008) gave groups options to either cooperate, defect with a benefit to the ingroup but no additional loss to the outgroup, or 
defect with a penalty to the outgroup but no benefit to the ingroup in an intergroup mixed-motive game. In all cases, groups chose the benefit to the ingroup choice. Thus, group behavior in these settings seems to be driven by motives to either protect or enhance (or both) the ingroup.

Two main perspectives describe the reasons for differences in the behavior of groups and individuals in mixed-motive situations (for reviews, see Cohen, Meier, Hinsz, \& Insko, 2010; Wildschut \& Insko, 2007). According to the fear-and-greed explanation, fear and greed characterize intergroup interactions more than they characterize interpersonal interactions (Cohen et al., 2010; Wildschut \& Insko, 2007; Wildschut et al., 2003). This explanation assumes that groups are more likely than individuals to be distrusted (i.e., people fear groups), and groups are more likely to attempt to maximize their own outcomes, either in an absolute or relative sense (i.e., groups are greedier than individuals). Groups, more than individuals, tend to be fearful of being taken advantage of by the other group. However, even when playing the game against a single individual, groups still are more likely to choose non-cooperation, thinking they can take advantage of the more cooperative individual (Morgan \& Tindale, 2002). Thus, groups both protect themselves by choosing non-cooperation, but also attempt to ensure that they do as well or better than the other player in the situation. Interestingly, there is little evidence that the effect stems from wanting to hurt the outgroup.

Morgan and Tindale (2002) showed this effect is at least partly due to asymmetries in the influence processes among the group members. Prior to making a group choice as to whether to cooperate or not, they asked each member to privately note their individual preference. Although preferences for cooperation were slightly lower when playing against a group, most individual members favored cooperation regardless of the type of opponent. Thus, most of the groups entered the discussion with majority factions favoring cooperation. However, minority factions 
favoring non-cooperation were quite persuasive and won out over cooperative majority factions two-thirds of the time, leading the majority factions to adopt a non-cooperative response. Majority factions favoring non-cooperation virtually never lost to minority factions favoring cooperation. Tindale (2008) argued that the shared motivation to protect or enhance the group (i.e., the group enhancement/protection norm) acted much like other shared task representations (described in more detail below) and made the non-cooperative response easier to defend because it was consistent with enhancing and protecting the ingroup.

Further evidence supporting the fear-and-greed explanation comes from studies using the PDG-Alt (Insko et al., 1990). The PDG-Alt is a variation of the prisoner's dilemma game described above; however, in this version of the game, a third choice (i.e., withdrawal) is added that guarantees equal intermediate outcomes (i.e., outcomes intermediate to those obtained when both players cooperate or both players compete) for both sides. In the PDG-Alt, competition is evidence of self-interest or greed whereas withdrawal is evidence of distrust or fear. In the PDGAlt, groups compete more, withdraw more, and cooperate less than individuals (Insko et al., 1990).

A second explanation for why group and individual behavior differ in mixed-motive situations is that groups are better at problem solving than individuals (Bornstein et al., 2004; Lodewijkx, Rabbie, \& Visser, 2006; Thompson et al., 1996). According to the group-decision making explanation, "two heads are better than one" when it comes to solving complex economic problems. Bornstein and his colleagues (Bornstein et al., 2004; Bornstein \& Yaniv, 1998) have provided evidence consistent with this explanation by showing that groups behave more consistently with game-theoretic predictions in economic games. Likewise, Thompson and colleagues (1996) found that groups were better than individuals at achieving Pareto-efficient 
outcomes (i.e., a state in which it is impossible to reallocate resources so as to make any one individual or preference criterion better off without making at least one individual or preference criterion worse off) in a multi-issue negotiation. However, because game-theoretic rationality and greed both involve self-interested behavior, there is some debate as to whether groups are actually more rational than individuals or whether they are simply more focused on winning or not losing (c.f., Bornstein et al., 2004; Lodewijkx et al., 2006; Wildschut \& Insko, 2007).

\section{Individual and Group Deception Differences}

Although many studies have compared intergroup and interpersonal interactions in mixed-motive economic games (e.g., Bornstein et al., 2004; Hargreaves Heap \& Zizzo, 2009; Wildschut et al., 2003), research comparing group and individual deception is scarce. In one of the few studies that investigates this topic, Sutter (2009) examined group and individual lying with the deception game (Gneezy, 2005). As previously described, the deception game is an economic decision-making task that requires one party (i.e., the sender) to send a truthful or deceptive message to another party (i.e., the receiver), and sending the truthful message potentially harms the sender's financial outcomes whereas sending the deceptive message makes it likely the sender will benefit financially (e.g., earn $\$ 6$ instead of $\$ 5$ ).

Research with the deception game has found that $36 \%$ of university students sampled lie (Gneezy, 2005) and men lie more than women (55\% to 38\%, respectively; Dreber \& Johannesson, 2008). Sutter (2009) found that groups lied less than individuals (23\% to $44 \%$, respectively) but suggested that this was a function of groups expecting to be distrusted (i.e., groups told the truth only because they expected their message to be disbelieved). Sutter's (2009) results are consistent with the fear-and-greed explanation of the discontinuity effect in that groups expected to be distrusted (i.e., fear) and they acted strategically to maximize their 
outcomes (i.e., greed). Sutter's (2009) findings suggest in certain circumstances, groups strategically use honesty to maximize their outcomes. However, as mentioned above, previous work has found groups choose uncooperative responses in economic games where such responses are not the dominant response (Bornstein \& Yaniv, 1998; Tindale et al., 2006). Therefore, it seems that motives to enhance or protect (or both) the ingroup at least partially explain Sutter's (2009) results.

Cohen and colleagues (2009) extended Sutter's (2009) work by testing whether groups are more deceptive than individuals when lying yields a higher payoff than honesty does. They used a modified version of the deception game (Gneezy, 2005), in which all of the participants sent a computer-mediated message about the payoffs to anonymous receivers (who did not exist). These receivers ostensibly chose between two payment options (each gave $\$ 5$ to one party and $\$ 6$ to the other) but they did not know which option gave them the higher payoff. Supposedly, the receivers would use the participants' message to guide their choice. Group payoffs were $\$ 15$ and $\$ 18$ respectively; they were required to divide the money equally. After talking about (in the group conditions) or thinking about (in the individual conditions) their message choice for three minutes, participants either told the truth or lied about the payoffs. In the study, the uncertain condition was the standard deception game, in which participants did not know whether the receiver would believe their message (Gneezy, 2005; Sutter, 2009). In the certain condition, participants learned that receivers had preemptively committed to following their payoff-choice recommendation. Thus, participants in the certain condition knew that receivers would choose the option they identified as giving receivers more money. These instructions made it clear that deception was guaranteed to give each participant $\$ 6$ and honesty was guaranteed to give each participant $\$ 5$. 
Cohen and colleagues (2009) found groups lied more than individuals when the receiver's response was certain, but groups lied relatively less than individuals when the receiver's response was uncertain. Specifically, when the message was certain to be followed, almost half of the individuals lied (48\%) but $82 \%$ of groups lied. Consistent with prior deception game studies (Gneezy, 2005; Sutter, 2009), when it was uncertain whether the message would be followed, $32 \%$ of individuals lied whereas $24 \%$ of groups lied. Not only did groups lie more when they were sure that they would be believed, they also reported more self-interest. Most groups who lied reported no qualms about using deception. Further analyses indicated that selfinterest explained why groups lied more than individuals when the receiver's response was certain. Previous research suggests groups are greedier than individuals and their greed fuels competition (Insko et al., 1990; Wildschut \& Insko, 2007). Cohen and colleagues' (2009) results suggest greed also seems to fuel deception.

Looking at the influence of compensation schemes on deceptive behavior, Conrads and colleagues (2013) employed a simple experimental design introduced by Fischbacher and Heusi (2008). Researchers compared the incentives to lie under two schemes: a team compensation scheme and an individual piece-rate scheme. Results revealed that under the team compensation scheme (i.e., the random production output of two agents was pooled and each agent received one half of a compensation unit for each unit of the joint production output), the marginal gain from lying (i.e., the return from exaggerating the own production output by one unit) was about half of the gain under the individual piece-rate scheme (i.e., for each unit of random production output, the agent received one compensation unit). These findings suggest that lying would is more pronounced under the individual piece-rate scheme than under the team incentive scheme. However, lying under the team incentive scheme is not exclusively beneficial for oneself, 
contrary to the individual compensation scheme. It also benefits the other agent in the team. Thus, an agent under a team incentive scheme, as opposed to an individual scheme, might be more able to justify such a lie. Indeed, this latter interpretation is also consistent with the group enhancement/protection norm (Tindale, 2008).

Supporting this idea, Conrads and colleagues (2013) found that lying was prevalent under both team incentives and individual piece-rate compensation schemes, but the effect was more pronounced under team incentives. This indicates that groups and organizations are well advised to be vigilant regarding potentially harmful side effects of compensation schemes. Those working under team incentives might be particularly prone to lying and deception because they might be able to more easily justify that lying led to a positive outcome (e.g., benefit other team members).

Deception driven by the motivation to enhance and/or protect the ingroup is a driving force behind organizational scandals. The fear and greed of groups seems to predispose them to lie more than individuals (c.f., Tindale et al., 1996; Wildschut \& Insko, 2007). In some situations, having groups make decisions may be particularly risky when organizations anticipate tradeoffs between ethics and self-interest. However, groups can also appear to be exemplars of honesty when there is a sense in the group that it is defined as being honest and trustworthy (e.g., Cohen et al., 2009; Stawiski, Tindale, \& Dykema-Engblade, 2009). Taken together, research suggests individuals and groups view honesty and deception differently. In particular, an ethical issue for individuals may be a strategic or normative issue for groups. Thus, whether groups will handle sensitive situations in an honest manner may depend on the group's preference for ethics or economics in that particular situation. However, these two preferences need not be mutually exclusive. 


\section{Framework}

To understand when and why groups use deception, we need to examine how groups process information. Group cognition consists of more than members simply sharing specific pieces of information and preferences (Resnick, Levine, \& Teasley, 1991; Tindale \& Kameda, 2000). Laughlin $(1980,2011)$ has argued that one of the reasons groups are better problem solvers than individuals is that group members often share a conceptual system that allows them to realize when a proposed solution is correct within that system. This shared conceptual system, or background knowledge, is what allows a minority faction with a correct answer to influence a larger incorrect faction to change its preference to the correct alternative. For example, suppose there is a group of five people discussing what $4^{2}$ is equal to. If all five group members understand the principles of arithmetic, then the group shares a conceptual system (i.e., they all have background knowledges about arithmetic they can apply to their current discussion).

These situations are well described by social decision scheme models, called truth wins and truth supported wins (Laughlin, 1980). Truth wins predicts that any group that has at least one member with the objectively correct answer will be able to solve the problem correctly (Laughlin, 1980). Truth supported wins argues that at least two members of the group must have the correct answer in order for the group to solve the problem correctly (Laughlin, 1980). For groups with more than four members, both models predict minority influence for minority factions with the objectively correct answer. Laughlin and Ellis (1986) proposed that such minority influence processes are likely to occur for demonstrable or intellective tasks (i.e., those that have a demonstrably correct solution) and that the shared conceptual system is a key component of demonstrability. For judgmental tasks (i.e., those without a demonstrably correct solution), majority/plurality processes are more likely to occur. 
Returning to the arithmetic example, even if four of the five group members believe $4^{2}$ is equal to 8 , as long as one of the five group members knows that $4^{2}$ is equal to 16 , then the group should arrive at 16 for their final decision. This is what he truth wins model predicts (i.e., only one person in the group needs to have the objectively correct answer). However, the truth supported wins model argues that at least two of the five need to know $4^{2}$ is equal to 16 for the group to produce the correct answer. Also, since there are more than four members in this hypothetical group, both models predict the minority faction should be able to convince the majority faction they have the correct answer. This minority influence is much more likely for a demonstrable task such as the current example (i.e., what is $4^{2}$ equal to) because it does have an objectively correct answer. If, for instance, the group were dealing with a judgmental task (e.g., determining guilt), the group would more likely endorse the majority faction's position because there is no objectively correct answer and the group's shared conceptual system is weaker.

Tindale, Smith, Thomas, Filkins, and Sheffey (1996) argued that the shared conceptual system underlying demonstrability is one instance of what they referred to as a shared task representation. They defined a shared task representation as "any task/situation relevant concept, norm, perspective, or cognitive process that is shared by most or all of the group members" (Tindale et al., 1996, p. 84). Task/situation relevant means the representation must have implications for the choice alternatives involved, and the degree to which a shared representation affects group decision processes and outcomes will vary as a function of its relevance. Its influence will also vary by the degree to which it is shared among the group members: the greater the degree of sharedness (i.e., the more members who share it), the greater its influence. If no shared task representation exists, or if multiple conflicting representations are present, groups will tend to follow a symmetric majority/plurality process. However, when a 
shared task representation does exist, the group decision process will tend to become asymmetric in favor of alternatives that fit within or are supported by the representation. Under such conditions, majorities/pluralities favoring an alternative consistent with the shared representation are more powerful than are identically sized majorities/pluralities favoring alternatives that are not consistent with or supported by the representation. In addition, minority factions favoring an alternative consistent with the shared representation can sometimes be more influential than majority factions favoring an alternative inconsistent with the shared representation, even when the majority is changing to a logically or normatively incorrect position (e.g., ignoring base rates).

A number of theories are consistent with or can explain the presence of an ingroup enhancement/protection norm. Social identity theory and self-categorization theory argue that group identification leads directly to ingroup favoritism and other behaviors that differentiate one's group from others (Hogg \& Abrams, 1988; Turner et al., 1987). Work on the role of groups in evolutionary adaptation of the species argues that living and hunting in groups had survival implications and being rejected by the group could lead to devastating outcomes such as starvation and death (Brewer \& Caporael, 2006; Levine \& Kerr, 2007). Additional simulation studies (Choi \& Bowles, 2007) have found that societies with a substantial number of members who are parochial altruists (i.e., those who sacrifice for the ingroup and shun or aggress against outgroup members) tend to be stable while societies with mainly non-exclusive altruists die off over time. More recent work has begun to isolate the physiological and neurological correlates of these effects and has shown that oxytocin helps to regulate responses to both ingroup and outgroup members (De Dreu, Greer, Handgraaf, Shalvi, et al., 2010). Thus, behaving in ways that favor the group welfare appears to be adaptive for both the group and the individuals that 
depend on it. Consequently, the group enhancement/protection norm is probably well ingrained in most group settings. Once group members begin to think of themselves as a group, they will begin to favor options that protect or enhance the group welfare. Thus, the group enhancement/protection norm serves as a shared task representation in that members share the norm (even if they do not explicitly recognize it), and behavioral options that are consistent with the norm will be more likely to be adopted than options inconsistent with the norm.

In many situations, such behavior will have few if any implications for people outside the group and may even be perceived as ethical both within and outside the group (e.g., helping a neighbor or family member, working extra hours to help insure the company does well this quarter). However, there are situations where group-serving behavior has negative consequences for the parties associated with the behavior and potentially society as a whole. For example, during the financial crisis of 2007-2008, predatory lending practices were very profitable for banks, and such profits were probably the motivating factor underlying these lending practices. It is unlikely that the banks were motivated to hurt the borrowers or create havoc in the economy. Yet, such behavior did, in fact, have such consequences and those consequences were foreseeable. Thus, many groups will not be prone to act unethically in all or even most situations, but they will often choose alternatives that are in their best interest, even when non-group members might perceive those choices as unethical.

So, if groups' natural tendencies are to behave in ways that support the groups' welfare and status, even when doing so leads to unethical behavior, how can we get groups to go against their nature and behave ethically? Work by Cohen and colleagues (2009) has shown making honesty a strategic choice that benefits the group will lead groups to be just as honest as individuals if not more so. However, changing strategic interests so ethical behavior leads to the 
best economic outcomes may not always be plausible. Another possible strategy is to make groups feel like their best or "true" interests are associated with ethical responses. In other words, one can try to change what the group (or its members) sees as "their nature" or "in their best interest". Research on social identity has shown that when group membership is salient (e.g., referencing an outgroup or increasing accountability to the ingroup), members' behavior tends to conform to what the members see as the group norm (Postmes \& Spears, 1998; Hogg \& Abrams, 1988). Thus, if a group member can create a sense that the group is defined as being honest and trustworthy, then such behaviors would be normatively correct within the group and may serve as a shared representation for tasks that involve ethical aspects. In other words, if the group members define the group as honest and trustworthy, the group enhancement/protection norm should encourage honest and trustworthy behavior because maintaining that positive identity is in the group's best interest. For example, consider a community that has suffered significant damage after a natural disaster. If the group enhancement/protection norm defines an trustworthy and cooperative group, the community will be much more likely to pull together and share resources after the disaster. However, if the group enhancement/protection norm defines a deceitful and non-cooperative group, the community will be unlikely to pull together and community members may lie to one another about the resources they actually have. Under such circumstances, groups may be more likely to behave in ways that protect and enhance the honesty and trustworthiness of the group and avoid the less ethical direction implied by economic issues.

De Dreu and colleagues (2008) developed a model of group judgment and decision making based on the combination of epistemic and social motives. Called the motivated information processing in groups (MIP-G) model, the model argues that information processing 
in groups is better understood by incorporating two somewhat orthogonal motives: (1) high versus low epistemic motivation (i.e., willingness to expend effort to achieve a thorough, rich, and accurate understanding of the world) and (2) prosocial (i.e., concerned with joint outcomes and fairness) versus proself (i.e., concerned with own outcomes) motivation. Earlier work on negotiation had shown that negotiators who shared high epistemic and prosocial motivations were better able to find mutually beneficial tradeoffs and reach better integrative agreements as compared to negotiators with any other combination of motives (De Dreu, 2010). Research now suggests the same appears to be true for groups working cooperatively to solve a problem or make a decision. According to the MIP-G model, high epistemic motivation involves a goal to be accurate or correct, which should lead to deeper and more thorough information search and analysis (Kruglanski \& Webster, 1996). Work on these information sharing effects has consistently demonstrated that instilling a goal of accuracy or defining the task in terms of solving a problem both increase information sharing (Postmes, Spears, \& Chiangir, 2001; Stewart \& Stasser, 1995). Members high in prosocial motivation help to insure that all types of information held by each member are likely to be disseminated, rather than just information supporting the position held by an individual member. Consistent with this assertion, other research has shown group members who focus on preferences rather than information tend to impede information sharing (Mojzisch \& Schutz-Hardt, 2010).

According to MIP-G, proself group members are less likely to input information conducive to group goals and collective functioning, they are less likely to disseminate information in an accurate way compared to prosocial group members. Proself group members are also more likely to spin information conducive to personal goals and preferences, to strategically withhold information, and to engage in lying and deception compared to prosocial 
group members (De Dreu et al., 2008). These tendencies should amplify when epistemic motivation among group members is high rather than low. For example, someone who is willing to expend effort to achieve a thorough, rich, and accurate understanding of the group situation (i.e., high epistemic motivation) is likely to seek out information until the group member is able to make sense of the situation. However, proself motivation biases the type of information the member looks for, generates, and processes. Thus, the group member is more likely to be concerned with self-interests and to ignore other group members' needs, interests, and beliefs (De Dreu et al., 2008).

This is because higher levels of epistemic motivation create a stronger tendency to deliberately and systematically process the information during group discussion. Also, higher levels of epistemic motivation reduce tendencies toward group centeredness and concomitant preference for autocratic leadership and reduced participative decision making. Thus, the MIP-G model predicts that group information processing will only approach optimal levels when group members are high on both epistemic motivation and prosocial orientation. This is because high epistemic motivation and prosocial orientation is the only combination that produces both systematic and thorough processing of information in an unbiased manner. Although the model is fairly recent, it does a good job of explaining a number of well-replicated findings and has fared well in the few direct attempts to test it (Bechtoldt, De Dreu, Nijstad, \& Choi, 2010; De Dreu, 2007).

\section{Implications and Conclusion}

In summary, we have argued, based on a large amount of empirical evidence, groups are naturally prone to behave in ways that enhance and/or protect the group. When people see themselves as part of a group, their responses become normative and form a framework within 
which members interpret their behaviors (i.e., a shared task representation). Thus, even if these group-normative responses are not initially favored by all of the group members, those members favoring such responses will tend to be quite persuasive. This tendency will not always make groups more unethical or deceptive than individuals, and in some cases, it may actually make groups more ethical and honest. However, whenever a group is making a decision that has implications for the welfare of the group, choice alternatives that enhance or protect the group welfare become easier to defend in the group discussion and will often be chosen by the group. Even in situations where an outside observer might define such responses as unethical (e.g., lying in a negotiation, failing to disclose relevant information, breaking former agreements), groups will still be prone to perform such unethical responses because these responses are perceived as normative and good for the group. However, other types of behaviors can also be seen as normative or "good for the group" depending on how the group defines itself. By changing how the group defines or views itself, it is possible to make other, more ethical responses appear normative and best for the group, and ultimately move the group in a more ethical direction.

While the empirical evidence does provide insight as to whether and when groups will be more likely to use deception than individuals, future work is certainly needed to further our understanding of deception within group contexts. In this chapter, we have proposed that the group enhancement/protection norm serves as a shared task representation in that members share the norm (even if they do not explicitly recognize it) and behavioral options that are consistent with the norm will be more likely to be adopted than options inconsistent with the norm. Additionally, we outlined De Dreu and colleagues' (2008) MIP-G model as another framework by which to conceptualize group deception use. We want to note that these 
frameworks are not necessarily mutually exclusive. It is completely conceivable that a group hold a shared task representation that signals high epistemic and high prosocial motivations. In such a conception, both frameworks would predict reduced deception and increased ethical behavior by groups. However, would these frameworks make the same predictions in both within and between group situations? That is, could high epistemic and high prosocial motivation lead to ethical decisions for within group situations but unethical decisions between groups due to the group protection/enhancement norm? How might altering the group's shared task representation influence these motivations and in turn group deception use? Future research should aim to dissect and clarify these and other relationships.

Many of today's most serious issues revolve around notions of ethics and how group membership can alter or exacerbate unethical tendencies in groups. From terrorism, to financial crises, to the political climate, a number of group-centric or group-serving ideas have been used to promote behavior that can often be perceived as unethical outside of the specific group context. The research covered in this chapter attempts to further understand the group-level variables that affect unethical and deceptive behavior and shows how groups might be able to use these same processes to attenuate or prevent deception. Research on mixed-motive situations has shown that groups tend to behave unethically and lie more often compared to individuals in the same situation. The fear and greed explanation argues groups are more likely than individuals to be distrusted (i.e., people fear groups), and groups are more likely to attempt to maximize their own outcomes, either in an absolute or relative sense (i.e., groups are greedier than individuals). This is also consistent with the idea that group members will behave in ways that are consistent with shared task representations such as the group enhancement/protection norm. Research in this area has also shown that group behavior in these settings is generally driven by concerns for 
the welfare of the ingroup rather than attempts to disadvantage the outgroup. Taken together, research points to the tendency for groups to lie and deceive more often than individuals because doing so often protects and enhances the ingroup's welfare. However, when being honest strategically benefits the group, its submerse will likely be just as honest — if not more so — than individuals in similar situations.

The potential benefits to society are vast if groups could be moved to behave more ethically by changing the ways group members perceive or think of the group or the task at hand. Because important decisions are often made by groups, and group-serving perspectives are commonly salient in such situations, obtaining a better understanding of how such perspectives affect groups and how they may be altered to enhance ethical concerns should prove valuable in numerous decision making contexts. Team and organizational leaders can use the knowledge generated from the literature discussed to implement strategies for facilitating more ethical decision-making in their own groups. For instance, team leaders could be trained on strategies for promoting ethical norms within their groups and to help teams adopt a promotion mindset (i.e., a emphasis towards progress, advancement, and gain rather than maintaining the status quo) once these norms are firmly established.

The theoretical perspectives and empirical findings covered here may also aid in designing educational and training materials that increase the role of ethics in decision-making. We hope groups and organizations will be able to use the information from the current chapter to enhance the role of ethics in leadership training. Similar techniques may be useful for designing role-playing exercises for business ethics courses and could be modified as exercises for critical thinking courses in high schools and colleges. This information may also help to inform policy 
issues associated with unethical behavior by groups in other domains (e.g., terrorist groups, gangs, juries). 


\section{References}

Bechtoldt, M. N., De Dreu, C. K., Nijstad, B. A., \& Choi, H. S. (2010). Motivated information processing, social tuning, and group creativity. Journal of personality and social psychology, 99(4), 622.

Bornstein, G., Kugler, T., \& Ziegelmeyer, A. (2004). Individual and group decisions in the Centipede game: Are groups more "rational" players? Journal of Experimental Social Psychology, 40(5), 599-605.

Bornstein, G., \& Yaniv, I. (1998). Individual and group behavior in the ultimatum game: are groups more "rational" players?. Experimental Economics, 1(1), 101-108.

Brewer, M. B., \& Caporael, L. R. (2006). An evolutionary perspective on social identity: Revisiting groups. Evolution and social psychology, 143, 161.

Choi, J. K., \& Bowles, S. (2007). The coevolution of parochial altruism and war. Science, $318(5850), 636-64$

Cohen, T. R., Gunia, B. C., Kim-Jun, S. Y., \& Murnighan, J. K. (2009). Do groups lie more than individuals? Honesty and deception as a function of strategic self-interest. Journal of Experimental Social Psychology, 45(6), 1321-1324.

Cohen, T. R., Meier, B. P., Hinsz, V. B., \& Insko, C. A. (2010). Competitive group interactions: Why they exist and how to overcome them. In S. Schuman (Ed.), The Handbook for Working with Difficult Groups. (pp. 223-236). San Francisco: Jossey-Bass.

Conrads, J., Irlenbusch, B., Rilke, R. M., \& Walkowitz, G. (2013). Lying and team incentives. Journal of Economic Psychology, 34, 1-7.

De Dreu, C. (2007). Cooperative Outcome Interdependence, Task Reflexivity, and Team Effectiveness: A Motivated Information Processing Perspective. Journal of Applied 
Psychology, 92(3), 628-638.

De Deru, C. K. (2010). Social value orientation moderates ingroup love but not outgroup hate in competitive intergroup conflict. Group Processes \& Intergroup Relations, 13(6), 701713.

De Dreu, C. K., Greer, L. L., Handgraaf, M. J., Shalvi, S., Van Kleef, G. A., Baas, M., ... \& Feith, S. W. (2010). The neuropeptide oxytocin regulates parochial altruism in intergroup conflict among humans. Science, 328(5984), 1408-1411.

De Dreu, C. K., Nijstad, B. A., \& van Knippenberg, D. (2008). Motivated information processing in group judgment and decision making. Personality and Social Psychology Review, 12(1), 22-49.

Dreber, A., \& Johannesson, M. (2008). Gender differences in deception. Economics Letters, 99(1), 197-199.

Fischbacher, U., \& Heusi, F. (2008). Lies in disguise: An experimental study on cheating. Research Paper Series, Thurgau Institute of Economics and Department of Economics at the University of Konstanz.

Gneezy, U. (2005). Deception: The role of consequences. The American Economic Review, 95(1), 384-394.

Halevy, N., Bornstein, G., \& Sagiv, L. (2008). "In-group love” and "out-group hate" as motives for individual participation in intergroup conflict: A new game paradigm. Psychological science, 19(4), 405-411.

Hargreaves Heap, S. P., \& Zizzo, D. J. (2009). The value of groups. The American Economic Review, 99(1), 295-323.

Hogg, M. A., \& Abrams, D. (1988). Social identifications: A social psychology of intergroup 
relations and group processes. Florence, KY: Taylor \& Frances/Routledge.

Insko, C. A., Schopler, J., Hoyle, R. H., Dardis, G. J., \& Graetz, K. A. (1990). Individual-group discontinuity as a function of fear and greed. Journal of Personality and Social Psychology, 58(1), 68-79.

Kameda, T., \& Tindale, R. S. (2006). Groups as adaptive devices: Human docility and group aggregation mechanisms in evolutionary context. Evolution and social psychology, 317341.

Kameda, T., Tindale, R. S., \& Davis, J. H. (2003). Cognitions, preferences, and social sharedness: Past, present, and future directions in group decision making. Emerging perspectives on judgment and decision research, 458-485.

Keck, S. (2014). Group reactions to dishonesty. Organizational Behavior and Human Decision Processes, 124(1), 1-10.

Kruglanski, A. W., \& Webster, D. M. (1996). Motivated closing of the mind:" Seizing" and" freezing.". Psychological review, 103(2), 263.

Laughlin, P. R. (1980). Social combination processes of cooperative problem-solving groups on verbal intellective tasks. Progress in social psychology, 1, 127-155.

Laughlin, P. R. (2011). Group problem solving. Princeton, NJ: Princeton University Press.

Laughlin, P. R., \& Ellis, A. L. (1986). Demonstrability and social combination processes on mathematical intellective tasks. Journal of Experimental Social Psychology, 22(3), 177189.

Levine, J. M., \& Kerr, N. L. (2007). Inclusion and exclusion: Implications for group processes. In A. W. Kruglanski \& E. T. Higgins (Eds.), Social psychology: Handbook of basic principles (2nd ed., pp. 759-784). New York: Guilford Press. 
Lodewijkx, H. F., Rabbie, J. M., \& Visser, L. (2006). "Better to be safe than to be sorry": Extinguishing the individual-group discontinuity effect in competition by cautious reciprocation. European review of social psychology, 17(1), 185-232.

Messick, D. M. (2006). Ethics in groups: The road to hell. In E. Mannix, M. Neale, \& A. Tenbrunsel (Eds.), Research on Managing Groups and Teams: Ethics in Groups, 8. Oxford, UK: Elsevier Science Press.

Mojzisch, A., \& Schulz-Hardt, S. (2010). Knowing others' preferences degrades the quality of group decisions. Journal of Personality and Social Psychology, 98, 794-808. doi: 10. 1037/a0017627

Morgan, P. M., \& Tindale, R. S. (2002). Group vs individual performance in mixed-motive situations: Exploring an inconsistency. Organizational Behavior and Human Decision Processes, 87(1), 44-65.

Pinter, B., Insko, C. A., Wildschut, T., Kirchner, J. L., Montoya, R. M., \& Wolf, S. T. (2007). Reduction of interindividual-intergroup discontinuity: the role of leader accountability and proneness to guilt. Journal of Personality and Social Psychology, 93(2), 250.

Postmes, T., \& Spears, R. (1998). Deindividuation and Antinormative Behavior: A MetaAnalysis. Psychological Bulletin, 123(3), 238-259.

Postmes, T., Spears, R., \& Cihangir, S. (2001). Quality of decision making and group norms. Journal of personality and social psychology, 80(6), 918.

Resnick, L. B., Levine, J. M., \& Teasley, S. D. (1991). Perspectives on socially shared cognition. Washington, DC: American Psychological Association.

Schopler, J., \& Insko, C. A. (1992). The discontinuity effect in interpersonal and intergroup relations: Generality and mediation. European review of social psychology, 3(1), 121- 
151.

Shaw, W. H., \& Barry, V. E. (2001). Moral issues in business (8thth ed.). Belmont, CA: Wadsworth.

Stasser, G., Kerr, N. L., \& Davis, J. H. (1989). Influence processes and consensus models in decision-making groups. In P. B. Paulus (Ed.), Psychology of group influence (2nd ed., pp. 279-326). Hillsdale, NJ: Lawrence Erlbaum Associates, Inc.

Stawiski, S., Tindale, R. S., \& Dykema-Engblade, A. (2009). The effects of ethical climate on group and individual level deception in negotiation. International Journal of Conflict Management, 20(3), 287-308.

Stewart, D. D., \& Stasser, G. (1995). Expert role assignment and information sampling during collective recall and decision making. Journal of personality and social psychology, 69(4), 619 .

Sutter, M. (2009). Individual behavior and group membership: Comment. The American Economic Review, 99(5), 2247-2257.

Thompson, L., Peterson, E., \& Brodt, S. E. (1996). Team Negotiation: An Examination of Integrative and Distributive Bargaining. Journal of Personality and Social Psychology, 70(3), 66-78.

Tindale, R. S. (2008). The wisdom (an occasional lack thereof) of groups. Presidential Address presented at the Midwestern Psychological Association Annual Convention, Chicago, IL.

Tindale, R. S., \& Kameda, T. (2000). 'Social sharedness' as a unifying theme for information processing in groups. Group Processes \& Intergroup Relations, 3(2), 123-140.

Tindale, R. S., Morgan, P., Stawiski, S., Dykema-Engblade, A., Meisenhelder, H., Wittkowski, E., \& Jacobs, E. (2006). Further explorations of the individual-group discontinuity 
effect. Paper presented at the First Annual INGRoup Conference, Pittsburgh, PA.

Tindale, R. S., Smith, C. M., Thomas, L. S., Filkins, J., \& Sheffey, S. (1996). Shared representations and asymmetric social influence processes in small groups. Understanding group behavior: Consensual action by small groups, 81-103.

Turner, J. C., Hogg, M. A., Oakes, P. J., Reicher, S. D., \& Wetherell, M. S. (1987). Rediscovering the social group: A self-categorization theory. Basil Blackwell.

Wildschut, T., \& Insko, C. A. (2006). A paradox of individual and group morality: Social psychology as empirical philosophy. In P. A. M. Van Lange (Ed.), Bridging social psychology: Benefits of transdisciplinary approaches (pp. 377-384). Hillsdale, NJ: Erlbaum.

Wildschut, T., \& Insko, C. A. (2007). Explanations of interindividual-intergroup discontinuity: A review of the evidence. European Review of Social Psychology, 18(1), 175-211.

Wildschut, T., Pinter, B., Vevea, J. L., Insko, C. A., \& Schopler, J. (2003). Beyond the group mind: A quantitative review of the interindividual-intergroup discontinuity effect. Psychological Bulletin, 129(5), 698-722.

Wildschut, T., Insko, C. A., \& Pinter, B. (2007). Interindividual-intergroup discontinuity as a joint function of acting as a group and interacting with a group. European Journal of Social Psychology, 37(2), 390-399. 